\title{
An end-fire low profile patch antenna to work on WiMAX frequencies used for harvesting power supply
}

\author{
Anwer Sabah Mekki ${ }^{1}$, Siba Monther Yousif ${ }^{2}$, Bashar Mudhafar Ahmed ${ }^{3}$, Mustafa Mohammed Jawad ${ }^{4}$ \\ ${ }^{1,4}$ Department of Medical Devices Techniques Engineering, Al-Turath University College, Iraq \\ ${ }^{2,3}$ Department of Electronic and Communications Engineering, College of Engineering, Al-Nahrain University, Iraq \\ ${ }^{3,4}$ School of Electrical Engineering, Faculty of Engineering, Universiti Teknologi Malaysia, Johor Bahru, Malaysia
}

\begin{tabular}{l}
\hline Article Info \\
\hline Article history: \\
Received May 22, 2021 \\
Revised Jul 27, 2021 \\
Accepted Aug 6, 2021 \\
\hline
\end{tabular}

\section{Keywords:}

End-fire

Harvesting power supply

High gain

Low profile

WiMAX

\begin{abstract}
In this paper, an end-fire microstrip patch antenna (MPA) is proposed of 3 $\mathrm{GHz}$ as a center frequency, designed, simulated, and measured to work on WiMAX frequencies within standard of 802.16e (WiMAX). A high gain ranged between (12.117-13.324) $\mathrm{dB}$, high front to back ratio (F/B) of (35.770) at the center frequency, a wide band of $1.701 \mathrm{GHz}$, low profile, and semi-ideal voltage standing wave ratio (VSWR) of 1.053 is achieved. The simulation is done using computer simulation technology (CST-MW). The proposed design is based on two Fire-retardant substrates (FR-4) of relative permittivity $(\varepsilon)$ $4.3+\mathrm{j} 0.025$ and $1.53 \mathrm{~mm}$ thickness for each one, which is considered a high loss material. The measurement results show good agreement with the simulated results. In addition, the design can be used for harvesting power supply from mobile towers. Finally, the proposed design is compared with two other designs in terms of power conversion efficiency and overall size.
\end{abstract}

This is an open access article under the CC BY-SA license.

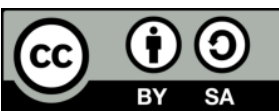

Corresponding Author:

Anwer Sabah Mekki

Department of Medical Devices Techniques Engineering

Al-Turath University College, Iraq

Email: anwer.sabah@turath.edu.iq

\section{INTRODUCTION}

The microstrip patch antenna (MPA) suffered from two well-known disadvantages, which are low gain and narrow bandwidth, although in many applications, a wide range and high gain MPA is required. MPA has very good specifications, such as low cost, easy to fabricate, and small surface area [1]-[4]. That is the reason behind many researchers are working to design their antennas considering the MPA technique and using different materials as well as different methods and designs to gain optimum parameters, which are required for their applications. New technologies such as using screen printing of conductive paint and using sticky copper film [5]-[7] as well as finding new designs that can affect the gain and the bandwidth of the MPA [8]. The complicated relationships between different parameters of MPA make the control on MPA parameters very sophisticated and it is very hard to get high gain and wideband at the same time [9]. A high gain antenna and good matching impedance are important goals for many applications. A multi-layer antenna is used to get an 11.5 dB Gain of an MPA for wireless application [10], and X band applications [11] and [12].

The significant end-fire specification is the direction of the propagation, which is laying in $\mathrm{X}$ or $\mathrm{Y}$ direction rather than $\mathrm{Z}$ direction, and that will be a great advantage to increase the gain of the design. The end-fire antenna has a great advantage, such as high directivity, low side-lobe, and high front-to-back ratio (F/R). Scientists have used many designs to get the end-fire specifications, such as Yagi antenna and antipodal antenna, which are the most well-known designs for the end-fire antenna. Moreover, due to the simplicity of using the microstrip technique, most researchers try to use the MPA technique to achieve this 
goal. One of the most widely used designs for getting an end-fire antenna is the use of an antenna array [13][16]. Others used bow-tie design to achieve end-fire antenna [17]. Zhang and Huang in [18] and Gajibo et al. [19], a design of a tree antenna with a dish reflector is used for end-fire antenna while a design derived from Yagi Uda antenna is proposed in [20]. other authors used reflectors to increase the F/B ratio and gain [21] and [22]. In this work, an end-fire antenna is used as a frequency receiver to collect the power transmitted from mobile towers. The proposed design overcomes polarization-independent cross-dipole design in [23] in terms of overall size and conversion efficiency and dual polarized metasurface design proposed in [24] in term of overall size.

\section{ANTENNA DESIGN}

From theoretical analyses of conventional MPA, the design is proposed. The theoretical equations are so limited due to limited number of variables. Moreover, they are based on two familiar designs, which are square patch and circular patch antenna. Therefor, for any arbitrary shape design, a simulator should be used. There are many reasons to use simulator program such as extra number of variables, method of solution, which depends on finite element method (FEM), the flexibility of presenting the output results, and the great agreement with measurement results. CST-MW allows optimizing the design to get the best results by sweeping some effective parameters through theoretical equations, these changes can make the design more reliable before implementation. The design dimensions are shown in Figure 1 and Figure 2 shows the antenna design.

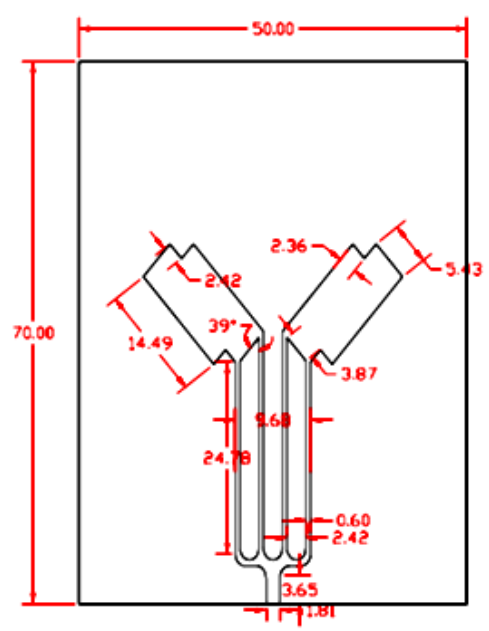

Figure 1. Dimensions of MPA in mm

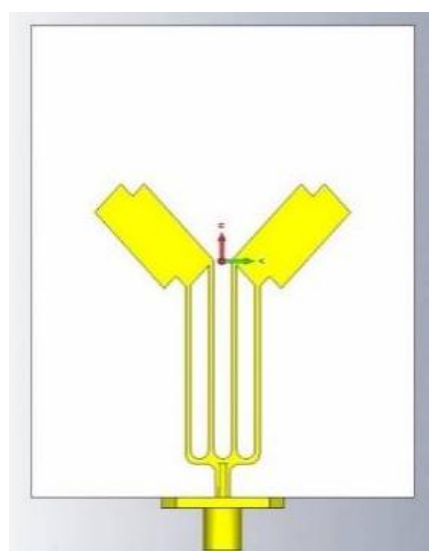

(a)

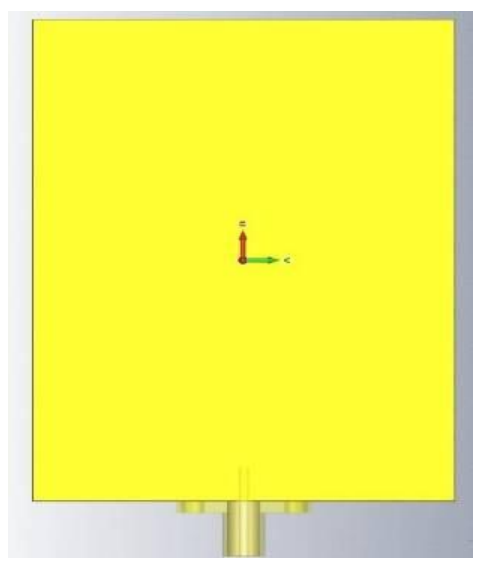

(b)

Figure 2. These figures are, (a) MPA face, (b) MPA ground layer 
The MPA is based on double stacked layers of FR-4 as a substrate, which is high lossy material of epsilon (4.43+j 0.025). These double layers will increase the bandwidth of the resonance frequency. The total volume of the proposed antenna is $(70 \times 50 \times 3.132) \mathrm{mm}^{3}$ as $\mathrm{L} \times \mathrm{W} \times \mathrm{H}$ and the length of four fork shape is approximately equal to $\lambda / 4$ where $\lambda$ is the free space wavelength of $3 \mathrm{GHz}$. Table 1 illustrated the parameters of the proposed design.

Table 1. Parameters of the proposed MPA

\begin{tabular}{lccc}
\hline \multicolumn{1}{c}{ Parameter } & Name & Value & Unit \\
\hline $\begin{array}{l}\text { Center frequency } \\
\text { Conductive material }\end{array}$ & Copper & 3 & $\mathrm{GHz}$ \\
$\begin{array}{l}\text { Conductive thickness } \\
\text { 1st layer of the substrate }\end{array}$ & FR-4 & 0.035 & $\mathrm{~mm}$ \\
2nd layer of the substrate & FR-4 & & \\
Substrate thickness & & 1.53 & $\mathrm{~mm}$ \\
Distance between substrates & & zero & $\mathrm{mm}$ \\
Single substrate thickness & & 1.53 & $\mathrm{~mm}$ \\
Substrate permittivity $(\varepsilon)$ & & $4.3+\mathrm{j} 0.025$ & \\
Connector & SMA & 50 & $\Omega$ \\
\hline
\end{tabular}

\section{RESULTS AND ANALYSIS}

\subsection{Simulation results}

In this work, a computer simulation technology (CST-MW) is used to simulate the proposed design. The design started from four fork shapes of $25 \mathrm{~mm}$ long, which is equal to $\lambda / 4$. Then, by considering the effecting of the square shapes, their surface areas, and their distribution on the FR-4 layer, the design is proposed. Finally, the shape of the antenna's design is finalized by optimizing the desired parameters. A wideband frequency with a center of $3 \mathrm{GHz}$ is achieved.

The simulation results show that the design is an end-fire antenna which indicates that the gain of MPA can reach a high value depending on the design's shape itself even though a high lossy material is used such as FR-4, and this is one of the main challenges in this design. Wideband which is equal to 0.566 of center frequency achieved using a double-stacked layer of a lossy FR-4 layer [25]. This wideband covers the bands $1,2,3,4$, and 5 of 802.16 e (WiMAX) [26]. Moreover, the F/B is equal to $35.77 \mathrm{~dB}$ at the center frequency which indicates a very good result without using any kind of reflector.

The simulation results achieve the parameters which are designed for harvesting power supply from WiMAX frequencies bands 1, 2, 3, 4, and 5. Moreover, the design can be used as a point-to-point WiMAX transmitter-receiver. Furthermore, the total thickness of the proposed antenna indicates that the design is low profile. The frequency response through the range $(0-10) \mathrm{GHz}$ and other parameters of the proposed design are listed in Table 2. In Figure 3, it can be seen that the End-fire far-field direction of the proposed antenna increases the gain of MPA in the direction of X. The E-field and H-field are shown in Figure 4 and the F/B ratio is shown in Figure 5.

Table 2. Parameters of the frequency responses in the

\begin{tabular}{lcc}
\multicolumn{3}{c}{ range (0-10) $\mathrm{GHz}$} \\
\hline \multicolumn{1}{c}{ Parameter } & Value & $\mathrm{Unit}$ \\
\hline Center frequency & 3.01 & $\mathrm{GHz}$ \\
Bandwidth & 1.719 & $\mathrm{GHz}$ \\
Bandwidth frequency starts from & 2.387 & $\mathrm{GHz}$ \\
Bandwidth frequency ends to & 4.106 & $\mathrm{GHz}$ \\
Substrate length & 70 & $\mathrm{~mm}$ \\
Substrate width & 50 & $\mathrm{~mm}$ \\
$S_{11}$ at center frequency & -30.979 & $\mathrm{~dB}$ \\
Directivity at the center frequency & 12.3 & $\mathrm{dBi}$ \\
Gain at the center frequency & 12.2 & $\mathrm{~dB}$ \\
Average gain at the bandwidth & 12.13 & $\mathrm{~dB}$ \\
VSWR & 1.058 & \\
Single side lobe & -14.2 & $\mathrm{~dB}$ \\
Average F/B & 31.368 & $\mathrm{~dB}$ \\
Linear radiation efficiency & 0.965 & \\
Main lobe direction & 141 & $\mathrm{deg}$. \\
Average front to back ratio & 37.868 & $\mathrm{~dB}$ \\
Total thickness of the antenna & 3.13 & $\mathrm{~mm}$ \\
\hline
\end{tabular}

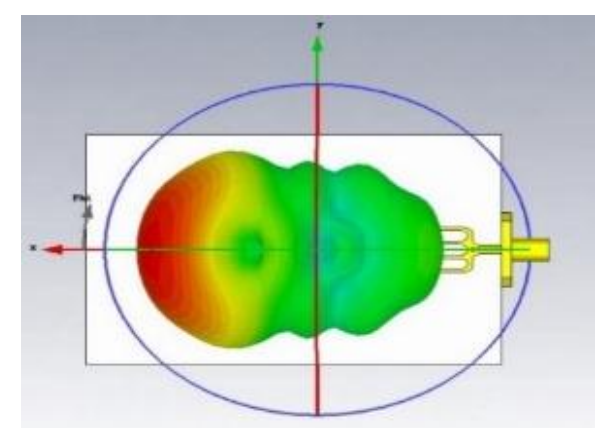

Figure 3. Top view of far-field plot 


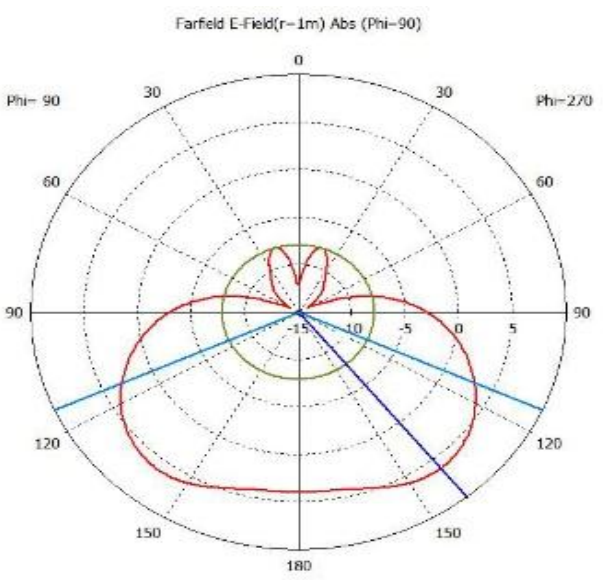

Theta / Degree ws. dev/m

(a)

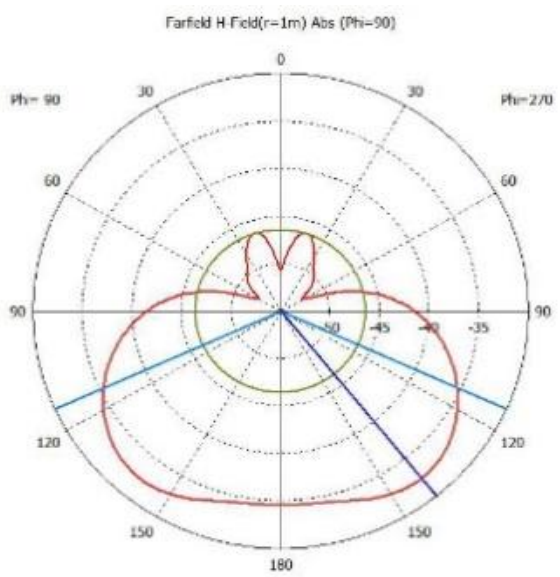

Theta/ Degee ws. dnA/m

(b)

Figure 4. These figures are, (a) E- Farfield, (b) H-Farfield

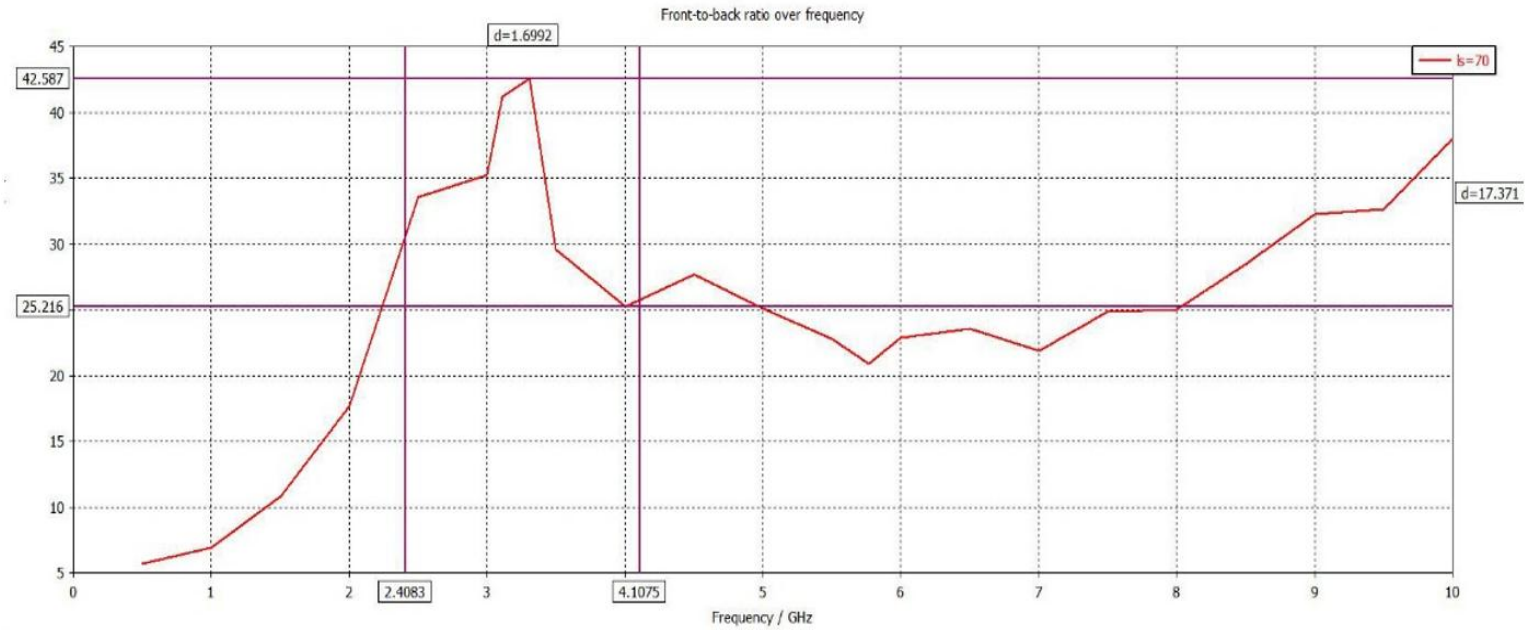

Figure 5. F/B ratio over the testing bandwidth

\subsection{Measurement results}

The proposed patch antenna is printed on two Fr-4 layers stacked together, with a fully copper ground layer. A perspective view of the proposed MPA is shown in Figure 6. The implemented antenna shows good agreement in comparison with the simulated design. Table 3 illustrated the measured paramerters of the proposed design. The setup used for the measurement are vector network analyzer (VNA) agilent E5071C, function generator type agilent N5183A, and two horn antennas. Figure 7 shows the S11 parameter of the simulated and measured design.

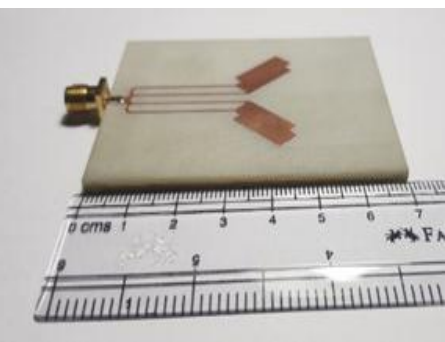

Figure 6. A perspective view of the fabricated proposed MPA 
Table 3. Fabricated parameters of the proposed design

\begin{tabular}{lcc}
\hline \multicolumn{1}{c}{ Parameter } & Fabricated values & Unit \\
\hline Center frequency & 2.97 & $\mathrm{GHz}$ \\
Bandwidth & 1.45 & $\mathrm{GHz}$ \\
Bandwidth frequency starts from & 2.65 & $\mathrm{GHz}$ \\
Bandwidth frequency ends to & 4.1 & $\mathrm{GHz}$ \\
Substrate length & 70 & $\mathrm{~mm}$ \\
Substrate width & 50 & $\mathrm{~mm}$ \\
$S_{11}$ at center frequency & -28.9 & $\mathrm{~dB}$ \\
Gain at the center frequency & 11.1 & $\mathrm{~dB}$ \\
Average gain & 11.6 & $\mathrm{~dB}$ \\
\hline
\end{tabular}

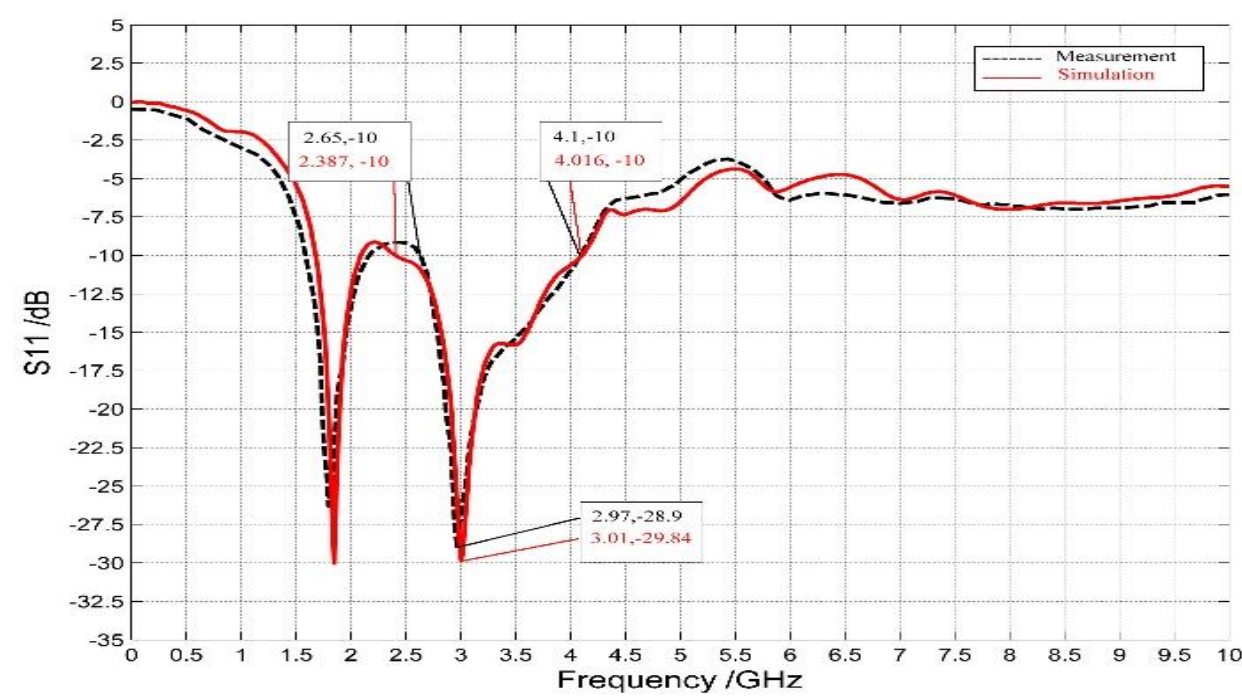

Figure 7. Simulated vs measured S11 of the proposed antenna

\section{HARVESTING CIRCUIT}

The antenna is designed for harvesting power supply from WiMAX frequencies scattered in the air. By using the specifications of the end-fire antenna, the efficiency of harvesting can be increased. Many methods used to harvest the energy from radio frequency (RF) signal [27]-[30], and the schematic diagram is shown in Figure 8.

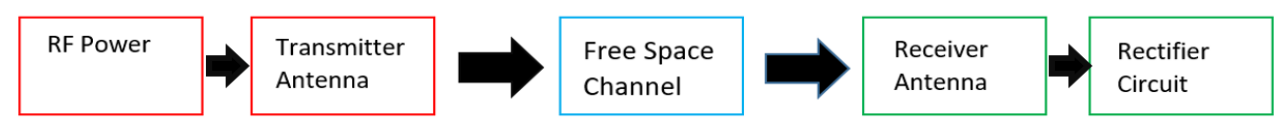

Figure 8. The Schematic diagram of harvesting power supply from RF energy

Many rectifier designs were implemented and used in this field [31], each one has its specifications and topology. In this paper, the Greinacher charge pump was used as shown in Figure 9, where $R_{L}=90 \mathrm{k} \Omega$ and $\mathrm{C}_{\mathrm{L}}=10 \mathrm{pF}$. The software used for harvesting is NI circuit design suite (multisim).

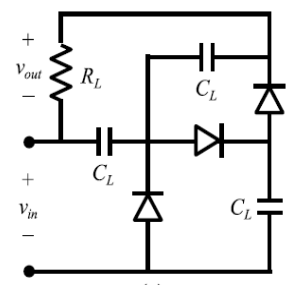

Figure 9. Greinacher charge pump 
The efficiency which is the most important parameter can be calculated from (1), where $P_{d c}$ is the output power and $P_{\text {in }}$ is the input power, is being as:

$$
\eta=P_{d c} / P_{i n}
$$

From simulation the input power is $0.5 \mathrm{~W}$ and the average output power is $0.41 \mathrm{~W}$ within the bandwidth. This means that the efficiency is equal to 0.82. Table 4 listed a comparison between this work and two other works. From Table 4, for the same center frequency, it can be seen that the proposed design overcomes the polarization-independent cross-dipole design proposed in [23] in terms of overall size as well as conversion efficiency. Moreover, the proposed antenna has a smaller overall size than the dual polarized metasurface design proposed in [24]. It is important to note that the proposed design covers a wider range of frequency than the two works as shown in Table 4.

Table 4. Comparison between this work and two other works

\begin{tabular}{ccccc}
\hline Reference & Dielectric Constant & Frequency & Size & Conversion Efficiency \\
\hline$[23]$ & 2.2 & $3 \mathrm{GHz}$ & $140 \times 140 \times 4.37$ & $74 \%$ \\
{$[24]$} & 2.2 & $3 \mathrm{GHz}$ & $70 \times 70 \times 3.175$ & $90 \%$ \\
This work & 4.3 & $3.01 \mathrm{GHz}$ & $70 \times 50 \times 3.13$ & $82 \%$ \\
\hline
\end{tabular}

The contribution of this paper is the use of an End-fire antenna design for harvesting power supply from RF. This will lead to convert electromagnetic wave into electric wave with high efficiency using small size of antenna due to the use of patch antenna technique without using any type of reflector layer. Moreover, it is important to note that the proposed design covers a wider range of frequencies than the two references in the comparison.

\section{CONCLUSION}

The End-fire antenna is an appropriate and active design for power harvesting applications, especially for good directivity which allows the antenna to harvest more power than other antenna designs. The proposed design is fabricated and measured. The measurement results show good agreements with the simulated results in terms of matching impedance, gain, center frequency, and bandwidth. Moreover, the proposed design has reduced the overall size by $87.2 \%$ and increased the conversion efficiency by $8 \%$ as compared with the polarization-independent cross-dipole design. Furthermore, the proposed design has reduced the overall size by $29.58 \%$ while decreasing the conversion efficiency by $8 \%$ as compared with the dual polarized metasurface design.

\section{REFERENCES}

[1] R. Garg, P. Bhrria, I. Bahl, and A. Ittipiboon, "Microstrip Antenna Design Handbook," Artech House Boston, London, 2001.

[2] D. G. Fang, "Antenna Theory and Microstrip Antennas," Taylor \& francis Group, 2010.

[3] Firdaus, A. N. Fatimah, Yulindon, and R. Dewi, "Design and comprehensive testing a $2.4 \mathrm{GHz}$ antenna for WiFi access point," TELKOMNIKA Telecommunication, Computing, Electronics and Control, vol. 18, no. 3, pp. 11761184, June 2020, doi: 10.12928/TELKOMNIKA.v18i3.14940.

[4] M. M. Jawad, N. N. N. A. Malik, N. A. Murad, M. R. Ahmad, M. R. M. Esa, and Y. M. Hussein, "Design of substrate integrated waveguide with minkowski-sierpinski fractal antenna for wban applications," Bulletin of Electrical Engineering and Informatics, vol. 9, no. 6, pp. 2455-2461, December 2020, doi: 10.11591/eei.v9i6.2194.

[5] I. H. Hasan, et al., "YIG Thick Film as Substrate Overlay for Bandwidth Enhancement of Microstrip Patch Antenna," in IEEE Access, vol. 6, pp. 32601-32611, 2018, doi: 10.1109/ACCESS.2018.2842749.

[6] W. G. Whittow, et al., "Inkjet-Printed Microstrip Patch Antennas Realized on Textile for Wearable Applications," in IEEE Antennas and Wireless Propagation Letters, vol. 13, pp. 71-74, 2014, doi: 10.1109/LAWP.2013.2295942.

[7] A. Jaiswal, M. P. Abegaonkar, and S. K. Koul, "Highly Efficient, Wideband Microstrip Patch Antenna With Recessed Ground at $60 \mathrm{GHz}, "$ in IEEE Transactions on Antennas and Propagation, vol. 67, no. 4, pp. 2280-2288, April 2019, doi: 10.1109/TAP.2019.2894319.

[8] D. De and P. K. Sahu, "An Investigation on End-fire Radiation from Linearly Polarized Microstrip Antenna for Airborne Systems," Progress In Electromagnetics Research M, vol. 59, pp. 9-24, 2017, doi: 10.2528/PIERM17052205.

[9] Chi-Lun Mak, H. Wong, and Kwai-Man Luk, "High-gain and wide-band single-layer patch antenna for wireless communications," in IEEE Transactions on Vehicular Technology, vol. 54, no. 1, pp. 33-40, Jan. 2005, doi: 10.1109/TVT.2004.838899.

[10] S. N. Nafea, A. Ismail, and R. S. A. R. Abdullah, "Low Side Lobe Level Multilayer Antenna for Wireless An end-fire low profile patch antenna to work on WiMAX frequencies used for ... (Anwer Sabah Mekki) 
Applications," Progress In Electromagnetics Research Letters, vol. 58, pp. 105-111, 2016, doi: 10.2528/PIERL15112202.

[11] J. Kumar, B. Basu, F. A. Talukdar, and A. Nandi, "X-band antenna printed on a multilayered substrate," IET Microwaves, Antennas \& Propagation, vol. 11, no. 11, pp. 1504-1509, 2017, doi: 10.1049/iet-map.2017.0197.

[12] H. Yon, N. H. Abd Rahman, M. A. Aris, and H. Jumaat, "Developed high gain microstrip antenna like microphone structure for 5G application," International Journal of Electrical and Computer Engineering (IJECE), vol. 10, no. 3, pp. 3086-3094, June 2020, doi: 10.11591/ijece.v10i3.pp3086-3094.

[13] Y. J. Cheng, W. Hong and K. Wu, "Design of a Monopulse Antenna Using a Dual V-Type Linearly Tapered Slot Antenna (DVLTSA)," in IEEE Transactions on Antennas and Propagation, vol. 56, no. 9, pp. 2903-2909, Sept. 2008, doi: 10.1109/TAP.2008.928797.

[14] Y. J. Cheng and Y. Fan, "Millimeter-Wave Miniaturized Substrate Integrated Multibeam Antenna," in IEEE Transactions on Antennas and Propagation, vol. 59, no. 12, pp. 4840-4844, Dec. 2011, doi: 10.1109/TAP.2011.2165497.

[15] G. R. DeJean, T. T. Thai, S. Nikolaou, and M. M. Tentzeris, "Design and Analysis of Microstrip Bi-Yagi and Quad-Yagi Antenna Arrays for WLAN Applications," in IEEE Antennas and Wireless Propagation Letters, vol. 6, pp. 244-248, 2007, doi: 10.1109/LAWP.2007.893104.

[16] J. Anguera, D. N. Uduwawala, S. Lanka, S. Lanka, and U. Ramon, "High-directivity genetic microstrip patch antenna," International Journal of Electronics Letters, vol. 4, no. 3, pp. 37-41, April 2015, doi: 10.1080/21681724.2015.1034189.

[17] N. O. Parchin, M. Shen and G. F. Pedersen, "End-fire phased array 5G antenna design using leaf-shaped bow-tie elements for 28/38 GHz MIMO applications," 2016 IEEE International Conference on Ubiquitous Wireless Broadband (ICUWB), 2016, pp. 1-4, doi: 10.1109/ICUWB.2016.7790538.

[18] J. Zhang and K. Huang, "A Novel Tree-Shaped Antenna with Wideband and End-fire Properties Designed by Competitive Algorithm of Simulating Natural Tree Growth," International Journal of RF and Microwave Computer-Aided Engineering, vol. 20, no. 3, pp. 342-346, 2009.

[19] M. M. Gajibo, M. K. A. Rahim, N. A. Murad, O. Ayop, and H. A. Majid, "Switchable wideband metamaterial absorber and AMC reflector for X-band applications and operations," TELKOMNIKA Telecommunication, Computing, Electronics and Control), vol. 16, no. 4, pp. 1535-1541, August 2018, doi: 10.12928/TELKOMNIKA.v16i4.9065.

[20] M. Jusoh, M. F. Jamlos, M. R. Kamarudin, F. Malek, M. H. Mat, and M. A. Jamlos, "A Novel Compact TreeDesign Antenna (NCTA) with High Gain Enhancement for UWB Application," Journal of Electromagnetic Waves and Applications, vol. 25, no. 17-18, pp. 2474-2486, April 2012, doi: 10.1163/156939311798806059.

[21] Z. Hu, Z. Shen, W. Wu, and J. Lu, "Low-Profile Top-Hat Monopole Yagi Antenna for End-Fire Radiation," in IEEE Transactions on Antennas and Propagation, vol. 63, no. 7, pp. 2851-2857, July 2015, doi: 10.1109/TAP.2015.2427853.

[22] A. S. Mekki, M. N. Hamidon, A. Ismail, and A. R. H. Alhawari, "Gain Enhancement of a Microstrip Patch Antenna Using a Reflecting Layer," International Journal of Antennas and Propagation, vol. 2015, October 2015, doi: $10.1155 / 2015 / 975263$.

[23] A. Z. Ashoor and O. M. Ramahi, "Polarization-Independent Cross-Dipole Energy Harvesting Surface," in IEEE Transactions on Microwave Theory and Techniques, vol. 67, no. 3, pp. 1130-1137, March 2019, doi: 10.1109/TMTT.2018.2885754.

[24] T. S. Almoneef, F. Erkmen, and O. M. Ramahi, "Harvesting the Energy of Multi-Polarized Electromagnetic Waves," Scientific Reports, vol. 7, no. 1, pp. 1-14, November 2017, doi: 10.1038/s41598-017-15298-5.

[25] D. Sarmah, N. S. Bhattacharyya, and S. Bhattacharyya, "Study of graded composite (LDPE/TIO2) materials as substrate for microstrip patch antennas in X-band," in IEEE Transactions on Dielectrics and Electrical Insulation, vol. 20, no. 5, pp. 1845-1850, Oct. 2013, doi: 10.1109/TDEI.2013.6633716.

[26] T. Ali and R. C. Biradar, "A compact multiband antenna using k/4 rectangular stub loaded with metamaterial for IEEE 802.11n and IEEE 802.16e," Microwave and Optical Technology Letters, vol. 59, no. 5, pp. 1000-1006, March 2017, doi: 10.1002/mop.30454.

[27] A. Taybi, A. Tajmouati, J. Zbitou, A. Errkik, M. Latrach, and L. El Abdellaoui, "A new design of high output voltage rectifier for rectenna system at $2.45 \mathrm{GHz}$," Indonesian Journal of Electrical Engineering and Computer Science, vol. 13, no. 1, pp. 226-234, January 2019, doi: 10.11591/ijeecs.v13.i1.pp226-234.

[28] T. L. Nguyen and D. T. Do, "Investigation on energy harvesting enabled device-to-device networks in presence of co-channel interference," TELKOMNIKA Telecommunication, Computing, Electronics and Control), vol. 19, no. 1, pp. 27-35, February 2021, doi: 10.12928/TELKOMNIKA.v19i1.16138.

[29] P. T. Tin, D. H. Ha, and T. T. Trang, "Adaptive relaying protocol for wireless energy harvesting and information processing in NOMA systems: Outage probability analysis," Bulletin of Electrical Engineering and Informatics, vol. 9, no. 1, pp. 94-100, February 2020, doi: 10.11591/eei.v9i1.1650.

[30] R. Radzuan, M. K. M. Salleh, N. A. Rhaffor, and S. K. K. Mohd, " $0.18 \mu \mathrm{m}-\mathrm{CMOS}$ rectifier with boost-converter and duty-cycle-control for energy harvesting," Bulletin of Electrical Engineering and Informatics, vol. 7, no. 2, pp. 161-168, June 2018, doi: 10.11591/eei.v7i2.1175

[31] Y. Chen and C. Chiu, "Maximum Achievable Power Conversion Efficiency Obtained Through an Optimized Rectenna Structure for RF Energy Harvesting," in IEEE Transactions on Antennas and Propagation, vol. 65, no. 5, pp. 2305-2317, May 2017, doi: 10.1109/TAP.2017.2682228. 


\section{BIOGRAPHIES OF AUTHORS}

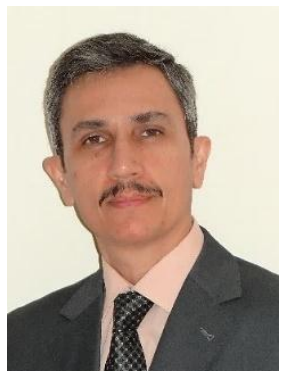

Anwer Sabah Mekki was born in Iraq, in 1968. He received B.Sc. degree in Electronic and Communications Engineering from University of Technology (UOT), Baghdad, Iraq, in 1992. He received $\mathrm{Ph} . \mathrm{D}$. degree in Electronic and Communications Engineering-Sensor Technology from Universiti Putra Malaysia (UPM), Malaysia, in 2016. He has many published papers and a patent in the field of sensors. Currently, he is the head of Medical Devices Techniques Engineering Department at Al-Turath University College, Baghdad, Iraq.

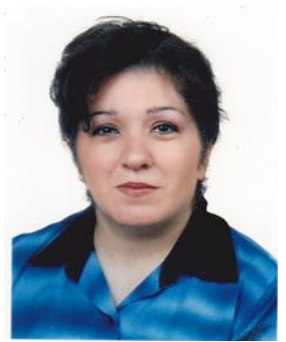

Siba Monther Yousif was born in Baghdad, Iraq, in 1970. She received B.Sc. degree in Electronic and Communications Engineering and M.Sc. degree in Electronics Engineering from University of Technology, Baghdad, Iraq, in 1992 and 2007, respectively. She received Ph.D. degree in Electronics Engineering from Universiti Putra Malaysia, Malaysia, in 2016. She has 12 years of experience in designing and developing electronic circuits. She joined the staff of the Department of Electronic and Communications Engineering at Al-Nahrain University, Baghdad, Iraq, since 2007.

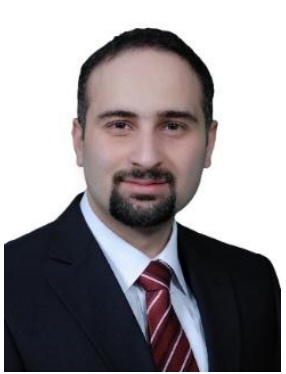

Bashar Mudhafar Ahmed was born in Baghdad, Iraq, in 1987. He obtained B.Sc. degree in Electronic and Communications Engineering from University of Baghdad, Iraq, in 2009 . He obtained M.Sc. degree in Electronic and Communications Engineering from Al-Nahrain University, Iraq, in 2014. He is a lecturer at the College of Engineering, Al-Nahrain University, Baghdad, Iraq. Currently, he is working toward a Ph.D. degree in Electronic and Communications Engineering at University of Babylon.

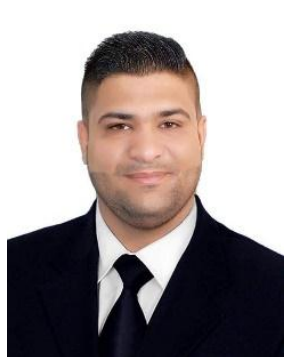

Mustafa Mohammed Jawad Abed was born in Baghdad, Iraq, in 1988. He received the B.Sc. degree in Computer Techniques Engineering from Al-Rafidain University College, Baghdad, Iraq, in 2010. He obtained M.Sc. degree in Electronic Engineering (Telecommunication System) from Universiti Teknikal Malaysia (UTEM) / Melaka, Malaysia, in 2018. Currently, he is studying for a $\mathrm{Ph} . \mathrm{D}$. degree in Electronic Engineering at Universiti Teknologi Malaysia (UTM), Johor Bahru, Malaysia. His current research focused on wireless body area network, frequency-selective surface, and substrate integrated waveguide antennas. 